\title{
Educação não é fabricação
}

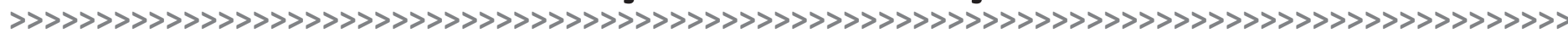

\author{
Kelly Cristine Correa da Silva Mota*
}

\section{Resumo:}

Este texto' constitui-se de reflexões a respeito do cotidiano escolar, especialmente no que se refere às relações pedagógicas entre professor e aluno, a partir de alguns conceitos de Philippe Meirieu, pesquisador francês contemporâneo. Basicamente, sustenta a defesa da ideia de que a educação escolar não pode se transformar em um projeto de fabricação do aluno pelo professor.

\section{Palavras-chave:}

Relação pedagógica. Solicitude. Educabilidade.

\section{Resumen:}

Este texto se compone de reflexiones sobre el cotidiano escolar, especialmente relativas a las relaciones pedagógicas entre professor y alumno, a partir de algunos conceptos de Philippe Meirieu, investigador francês contemporâneo. Básicamente defiende la idea de que la educación escolar no puede transformarse en un proyecto de fabricación del alumno por el profesor.

\section{Palabras clave:}

Relación pedagógica. Solicitud. Educabilidad.

\section{Introdução}

Atenta a algumas situações escolares cotidianas, que considero permeadas por contradições entre os fins da educação e as formas de atingi-los, busquei aportes teóricos em Philippe Meirieu ${ }^{2}$, principalmente, para problematizar essas contradições. Por contradições, naquele contexto, entendo dissociações entre o dizer e o fazer, resultando em desperdício de possibilidades pedagógicas. Há miudezas preciosas no dia a dia da escola que não são miúdas no sentido de pequenas, mas de habituais, repetitivas, circunscritas ao âmbito da sala de aula, a conexões interpessoais de curto alcance: movimentos que parecem não marcar a identidade pública da instituição, mas que, no entanto, são importantes para compreender a relação pedagógica que se estabelece - relação aqui entendida como todo o complexo cenário de encontro entre professor e aluno, permeado pela linguagem, pelo racional, pelo emocional, pela ética.

Assim, situações prosaicas sobre formas de avaliação da aprendizagem, ou soluções para conflitos verbais e físicos entre os alunos, são alguns desafios recorrentes. A meu ver, nessas circunstâncias, revela-se, de maneira nítida, todo potencial autoritário do professor e suas tentativas de moldar o aluno ao seu gosto. Muitas vezes, o docente

* > Professora de Sociologia no Colégio de Aplicação da Universidade Federal do Rio Grande do Sul (CAp-UFRGS). E-mail: kellysociologia@gmail.com e kelly.mota@ ufrgs.br

1 > Texto elaborado para o Seminário A Relação Pedagógica, ministrado pelo Prof. Dr. Cláudio Roberto Baptista, em 2013/1, no Programa de Pós-Graduação em Educação da Faculdade de Educação da Universidade Federal do Rio Grande do Sul (PPGEDU/FACED/UFRGS).

$2>$ Philippe Meirieu (França, 1949) é professor e pesquisador na área da Educação, doutor em Letras e Ciências Humanas. Lecionou em todos os níveis de ensino, em que realizou experiências pedagógicas e, a partir das quais problematiza tensões intrínsecas ao processo de formação escolar do ser humano, bem como argumenta em favor de reformas na instituição escolar. Atualmente é professor de Ciência da Educação na Universidade Lumière-Lyon 2 e coordena o Instituto de Ciências e Práticas de Educação e de Formação. 
guia-se por modos que não impulsionam a autonomia e que repetem padrões sociais de competição e classificação sem sentido para a aprendizagem. Dessa forma, é que percebo em funcionamento a concepção de educação como fabricação.

O professor exerce sua profissão entendendo-se como autoridade na sala de aula. E o é, no sentido de que tem responsabilidade de organizar o espaço de convivência que constitui o ensino; no entanto, há diferentes concepções sobre o que isso significa. Normalmente, vigora a ideia de que o professor é aquele cuja função é determinar, sozinho e definitivamente, o projeto educativo para a turma, aí estaria implícito, para cada aluno, o que seria bom e inquestionável.

\section{Breve discussão teórica}

Ocorre que, rapidamente, esquece-se que o ofício de aluno não é algo natural: o aluno aprende a ser aluno e, normalmente, não é dócil, mas resistente a esse processo. Segundo Meirieu (2002, p. 59), ele “[...] recusa, ignora, contesta, rejeita o que lhe é proposto", e é saudável que assim o seja, pois se trata de um movimento natural no processo de autoafirmação; tem que haver distanciamento para emergir autonomia de pensamento. Frequentemente, a indiferença pode se apresentar como uma maneira de lidar com essas situações, especialmente da parte do professor que, ao não se ver implicado, não age sobre suas próprias resistências. Da parte do aluno, rechaço e enfrentamento são as consequências.

Se não se tem clareza dessa configuração, as tentativas de interação acontecem na direção do aniquilamento do outro, isto é, da imposição unilateral de regras, dos modos de ser e de fazer, mesmo que isso signifique processos sem compreensão; o aluno atua de uma forma na superfície; aprende a se mover institucionalmente, para não reprovar, para manipular o professor, mas não assume a sua parte devida no projeto de formação humana. Mais potente, do ponto de vista educativo, entende o autor, é encarar a resistência do outro ${ }^{3}$ como um convite para ir ao seu encontro. "Quando não procuro quebrar a resistência do aluno, mas quebrar em mim aquilo que suscita tal resistência... a nuance poderá parecer insignificante: na realidade ela é essencial” (MEIRIEU, 2002, p. 78).

É tênue a fronteira, na relação pedagógica, entre o princípio da liberdade e o da não liberdade, entre o respeitar o tempo do outro e o tentar impor demandas que lhe são externas, entre as tentativas de controlá-lo e autorizá-lo. Como conciliar essas tensões? Mais do que optar por um ou outro aspecto, ou fornecer uma resposta definitiva, a intenção é provocar reflexões a respeito, de modo que se atente, constantemente, para a complexidade da situação e para o fato de que, é inerente ao exercício docente, a partilha do saber que se ensina. Dessa forma, não há possibilidade de ação ou relação pedagógica apenas com um dos polos.

Nesse sentido, o diálogo é o meio mais vigoroso de mediação, no aspecto educativo, para lidar com as resistências que persistirão sempre, uma vez que é intrínseco ao processo formativo humano um estado de tensão com aquilo que se quer superar. E dialogar/conversar supõe respeitar o engajamento e a resistência do outro, visto que carrega consigo vinculações sociais, afetivas, teóricas, expectativas, singulares, em relação a qualquer outro ser humano.

Maturana (1995) tem um belo texto intitulado Ontología del conversar, no qual

3 > Em síntese, o outro, na relação social, é o meu interlocutor, reconhecido como semelhante, porque tem o mesmo status de humano e de sujeito. Ao mesmo tempo, é o estranho, porque é o meu diferente, do ponto de vista teórico, social, cultural, geográfico etc. Ver: LEOPOLDO E SILVA, 2012. chama atenção para o fato de que conversar, conforme abordagem etimológica, e aqui é pertinente aproximar à noção de diálogo, é dar voltas com o outro. Nesse processo, é imprescindível a participação da linguagem como capacidade simbólica: constitui-nos humanos, possibilita a comunicação e também a manifestação da razão e da emoção. O conversar entrelaça o emocional e o racional e permite resolver nossos desacordos; sobretudo, porque o outro é percebido como legítimo nos seus argumentos, nas suas representações, nos seus afetos. 
Estar disponível para resolver desacordos por meio da conversa com o outro, de modo que possamos nos despir em parte das nossas certezas, perspectivas, abrir mão de tendências autoritárias, tuteladoras e, ao mesmo tempo, acolher suas especificidades, implica estabelecer elos de alteridade, de escuta, um estado de prontidão a ele. Meirieu sustenta que esse é o momento permeado pela ética, uma vez que diz respeito à minha responsabilidade com o outro. Há uma passagem, longa e belíssima, que esclarece seu entendimento a respeito. Em uma primeira parte da citação, há a consequência da ausência de comunicação, de diálogo. Diz assim:

É no estatuto de minha palavra que se coloca em jogo minha posição ética; se eu fizer dela um instrumento de sedução ou de dominação, se me agarrar a ela e endurecê-la quando sentir despontar a resistência de outro, se elevar a voz e descambar para a violência, se virar o rosto e deixar transparecer o desprezo, se me obstinar na repetição até o absurdo, meu discurso se fechará, ele se tornará uma espécie de totalidade que o outro não pode senão aceitar ou recusar em uma relação de forças da qual todo encontro e partilha acabam por ser excluídos. (MEIRIEU, 2002, p. 79).

A seguir, na continuidade do pensamento de Meirieu, reproduzo uma postura radicalmente oposta à citada acima, a qual o autor denomina de uma verdadeira ética da comunicação pedagógica:

[...] se eu reconhecer em meu discurso uma proposta que se ofereça à compreensão do outro, uma palavra que, sem negar nada de suas convicções e de sua conduta, deixa-se trabalhar internamente pela exigência de clareza, pela preocupação com o rigor e pela vontade de explicitar cada vez mais e melhor os desafios que comporta, se minha palavra não for totalidade, clausura, objeto acabado para pegar ou largar, mas se inserir deliberadamente no inacabado ou no inacabável... então algo poderá acontecer. (MEIRIEU, 2002, p. 79).

A disposição para essa postura dialógica, tal como exposta aqui, supõe, ao meu ver, adesão aos princípios da solicitude e da educabilidade. A verdadeira solicitude, afirma Meirieu, é a categoria da relação pedagógica que emerge como exigência ética, como preocupação comigo e com o outro, pelo seu futuro, e também pela incumbência em estimulá-lo a assumir seu projeto educativo; carregada, portanto, de afetividade porque enxerga o outro na sua singularidade. É querer "[...] interpelá-lo para que ele próprio se conduza” (MEIRIEU, 2002, p. 70). Ao lado disso, a educabilidade manifesta a convicção docente de que todo aluno é educável; a despeito da sua resistência, constitutiva da experiência pedagógica, há a aposta no sujeito, o compromisso de apresentar-lhe universos intelectuais e culturais alternativos, sem os quais o professor nem inicia seu efetivo trabalho.

\section{Considerações finais}

A partir dessas breves reflexões, amparadas em Meirieu, é que se pode considerar que sustentar a educação como fabricação é se amparar na fantasia do controle total sobre o outro, desconsiderando-o como sujeito de seu próprio projeto; é uma intenção atravessada por angústia, desencanto e fracasso pedagógico, dado que não se pode agir em seu lugar. Pode-se, modestamente, dirigir-se ao seu entendimento, oferecer-lhe um objeto de saber que o auxilie a ressignificar e expandir o conhecimento e a lucidez sobre si e sobre o mundo, a partir do seu lugar nas interações sociais e do modo como está (ou não) permeável às oportunidades pedagógicas. 


\section{Referências}

LEOPOLDO E SILVA, Franklin. O outro. São Paulo: WMF Martins Fontes, 2012.

MATURANA, Humberto. Ontología del conversar. In: La realidade: ¿objetiva o construída? Barcelona: Anthropos; México: Universidad Iberoamericana; Guadalajara: Instituto Tecnológico y de Estudios Superiores de Occidente (ITESO), 1995. p. 19-36.

MEIRIEU, Philippe. A pedagogia: entre o dizer e o fazer, a coragem de começar. Porto Alegre: Artmed, 2002. 